\title{
Semantic priming effects on picture and word processing
}

\author{
RICHARD D. SPERBER, CHARLEY MCCAULEY, RONNIE D. RAGAIN, \\ and CAROLYNE M. WEIL \\ Vanderbilt University, Nashville, Tennessee 37203
}

\begin{abstract}
The effects of semantic priming on picture and word processing were assessed under conditions in which subjects were required simply to identify stimuli (label pictures or read words) as rapidly as possible. Stimuli were presented in pairs (a prime followed by a target), with half of the pairs containing members of the same semantic category and half containing unrelated concepts. Semantic relatedness was found to facilitate the identification of both pictures (Experiment 1) and words (Experiment 2), and obtained interactions of semantic relatedness and stimulus quality in both experiments suggested that semantic priming affects the initial encoding of both types of stimuli. In Experiment 3, subjects received pairs of pictures, pairs of words, and mixed pairs composed of a picture and a word or of a word and a picture. Significant priming effects were obtained on mixed as well as unmixed pairs, supporting the assumption that pictures and words access semantic information from a common semantic store. Of primary interest was the significantly greater priming obtained in picturepicture pairs than in word-word or mixed pairs. This suggests that, in addition to priming that is mediated by the semantic system, priming may occur in picture-picture pairs that results from the overlap in visual features common to the pictorial representations of objects from the same semantic category.
\end{abstract}

When people are given information about the meaning of a stimulus in advance of its actual appearance, the time required for stimulus processing is frequently reduced (e.g., Rosch, 1975). This processing facilitation, or semantic priming effect, has been of interest to theorists concerned with modeling the structure of semantic memory (e.g., Collins \& Loftus, 1975), as well as to those concerned with the interaction of stored semantic information with perceptual encoding processes (e.g., Becker \& Killion, 1977; Meyer, Schvaneveldt, \& Ruddy, 1975).

Studies of semantic priming effects can be divided roughly into two classes in accordance with a distinction recently made by Neely (1977). In one class, priming effects may be assumed to result at least partially from conscious expectations developed by the subject as a result of either being told explicitly in the instructions that the prime is to be treated as a clue (e.g, Becker \& Killion, 1977; Neely, 1977) or being tested under experimental procedures in which the reason for the prime is made obvious (e.g., Rosch, 1975; Sanford, Garrod, \& Boyle, 1977). In the second class are studies in which priming effects may be assumed to arise relatively automatically (Posner \& Snyder, 1975), simply

This research was supported by Grants HD00973-15, HD04510-10, and HD07045 from the National Institute of Child Health and Human Development. The contribution of the first two authors to this paper was equal, and requests for reprints can be addressed to either Richard Sperber or Charley McCauley, Vanderbilt University, Peabody College Box 512, Nashville, Tennessee 37203 . as a by-product of subjects' having processed the prime. In this case, the processing of the prime ostensibly does not direct attention toward potential semantic relationships. Studies from the latter class are primarily ones in which semantic priming effects have been investigated within the framework of a lexical decision task (e.g., Fischler, 1977; Meyer et al., 1975).

Our interest in the present studies was in the more automatic type of semantic priming. Subjects were required in these experiments simply to identify stimuli (label pictures or read words) as rapidly as possible. Stimuli were presented in pairs (a prime followed by a target), but no mention was made of potential relationships among stimuli. Under these conditions, a semantic priming effect is inferred from a reduction in response times to targets in related pairs.

The first experiment specifically addressed the effects of priming on picture processing. Current theoretical accounts of semantic priming (e.g., Collins \& Loftus, 1975) are based entirely on data from experiments in which the stimuli were words. Since a picture is a good, albeit not exact, replica of the actual object it represents (cf. Hagen, 1978), it seems particularly important to demonstrate that semantic priming of the automatic type occurs with primes and targets that are similar to those encountered in ordinary visual information processing. A number of current memory models are consistent with the demonstration of such picture priming effects, and at least one model predicts automatic priming effects on picture processing explicitly (Seymour, 1973, 1976). However, there are currently 
no data that directly test the picture priming prediction, other than those obtained under conditions in which the purpose of the prime is made obvious (Rosch, 1975).

The second experiment was designed to assess the effects of semantic relatedness on word processing under conditions that were directly analogous to those used in Experiment 1 to assess picture priming, that is, under conditions in which subjects are required simply to read sequentially presented words as rapidly as possible. As noted above, several investigators have shown wordword priming effects on the speed with which subjects can make lexical decisions. However, the magnitude of relatedness effects on lexical decisions apparently depends on the nature of the nonwords used (Shulman \& Davison, 1977), a finding that leaves open the possibility that such priming effects may actually result from the structure of the lexical decision task per se. Meyer et al. (1975) have also demonstrated word-word priming in a pronunciation task in which no lexical decision was required; however, words were again mixed with nonwords, a manipulation that may or may not have induced a type of semantic processing different from that which typically occurs in ordinary reading. The present experiment examined word-word priming in an actual reading task.

The purpose of Experiment 3 was to directly assess the extent to which priming effects are larger for picturepicture pairs than for word-word pairs, as was suggested by the results of the first two experiments, and to specify the locus of this difference. In Experiment 3, each subject received pairs of words, pairs of pictures, and mixed pairs composed of a picture and a word. This design allowed us to determine (1) if the processing of picture targets is facilitated more by semantic relatedness than is the processing of word targets, and/or (2) if pictures serve as more effective primes than do words.

\section{EXPERIMENTS 1 AND 2}

In Experiment 1, subjects were shown pairs of pictures (a prime and a target) and were instructed to name each picture as rapidly as possible without making errors. Half of the picture pairs were of categorically related concepts, and half were of unrelated concepts. Unbeknownst to the subjects, only naming time to the target picture in each pair constituted the dependent measure. The design of Experiment 2 was essentially the same except that subjects were required to read words, rather than to name pictures, as rapidly as possible.

While there is clearly no consensus among theorists as to the format in which semantic information is represented in memory (see Anderson, 1978; Holland, 1975), current models of picture and word processing uniformly assume the existence of a single semantic store that can be accessed by both pictures and words (e.g., Paivio, 1978; Seymour, 1973, 1976). Since semantic priming effects of the automatic type have previously been reported with words, and since both pictures and words are assumed to make contact with a common semantic system, it would be expected that significant priming effects would obtain with pictures, as well as with words, under the present task conditions. However, if the priming effects obtained with words are the result of an influence of semantic information on a graphemic encoding stage, as suggested by Meyer et al. (1975), the absence of a directly analogous stage in pictorial encoding could mitigate the effect of semantic relatedness on picture processing.

One additional variable was included in Experiments 1 and 2 in an attempt to specify the locus of pictorial priming effects. In each experiment, half of the targets in related pairs and half of those in unrelated pairs were visually degraded (as described below). The results of several previous studies indicate that the processing of degraded words is facilitated by semantic relatedness to a greater extent than is the processing of clearly visible words (Becker \& Killion, 1977; Meyer et al., 1975; Sanford et al., 1977), and we expected to replicate this finding in Experiment 2. Since stimulus quality is assumed to affect the early encoding of words, the interaction of semantic relatedness and stimulus quality is generally interpreted as indicating that semantic priming also affects an initial encoding stage of word processing (see, e.g., Becker \& Killion, 1977). Thus, with respect to Experiment 1, we predicted that if priming affects an encoding process common to pictures and words (e.g, a visual feature extraction process) or there are different but analogous stages in picture and word encoding that are sensitive to the same independent variables (Seymour, 1976), then an interaction of relatedness and stimulus quality should obtain with pictures (Experiment 1) that resembles that predicted for words (Experiment 2).

\section{Experiment 1}

\section{Method}

Subjects. The subjects were 40 undergraduate students who were paid for their participation.

Materials. The stimuli were photographs of black-and-white line drawings, most taken from the Peabody Picture Vocabulary Test and the remainder drawn by an artist. Thirty-two pictures of common objects were selected from the stimulus pool and designated as target pictures. The selection criterion was that each target picture could be paired intuitively with another picture from the stimulus pool to form a categorically related pair (e.g., cat-horse, trumpet-guitar). Each of the target pictures was then re-paired with a different first picture to form a set of 32 unrelated pairs (e.g., trumpet-horse, cat-guitar). This procedure yielded a set of 64 picture pairs, half related and half unrelated, for use on experimental trials. An additional set of 20 unrelated pairs was formed from the remaining pictures in the stimulus pool for use on practice trials.

Stimulus quality was varied by photographing each of the 64 
target stimuli once "in focus" (clear condition) and once "out of focus" (degraded condition). Target pictures in the clear condition were photographed at a distance of $40 \mathrm{~cm}$, with the camera's focus appropriately set for that distance. Target pictures in the degraded condition were photographed at a distance of $40 \mathrm{~cm}$ with the focal distance set at $75 \mathrm{~cm}$. These camera settings were selected (based on pilot work) such that degraded pictures would be maximally blurred without significantly affecting subjects' response accuracy. All primes (first pictures in each pair) were of the clear type. This procedure yielded a total of 128 different picture pairs, with each of the 32 target concepts appearing once in each of the four conditions resulting from the factorial combination of relatedness (related, unrelated) and stimulus quality (clear, degraded).

It seemed possible that repetitions of target stimuli over the course of the experiment could have resulted in subjects' becoming familiar enough with the particular pictures employed so as to induce modifications in the perceptual strategies used to recognize the pictures. For example, it is possible that recognition of familiar pictures is based on the identification of fewer visual features than are required for recognizing relatively novel pictorial representations. Since such modifications in perceptual processing could potentially influence the extent to which semantic relatedness affects picture identification (the effect of stimulus repetitions on semantic priming was directly tested in Experiment 3), each target concept was presented only once to each subject. To accomplish this without sacrificing control for possible item differences across conditions, the 128 test pairs were divided into four sets of 32 pairs such that (1) the four experimental conditions were represented an equal number of times in each set, and (2) every target concept appeared once in each set. The 40 subjects were then divided into four groups, and each group was assigned a different stimulus set. Thus, across all subjects, each target concept appeared equally often in each of the four experimental conditions.

Apparatus. The apparatus consisted of a Kodak Carousel (Model C) slide projector equipped with a tachistoscopic lens for presenting pictures, a voice-operated relay wired to a Hunter Model 120-C Klockounter for recording naming latencies to target pictures, and supportive electromechanical equipment, including a timer to control the interval between pictures in each pair. The Klockounter was interfaced with the voice-operated relay and tachistoscopic lens such that the onset of the second picture in each pair started the timing cycle, and the subject's naming response stopped the cycle.

Procedure. The experimental session began with 20 practice trials on the picture-naming task. All practice pairs were of the unrelated type to ensure that any "set" or response bias that might be established during practice would work against obtaining the predicted relatedness effect. Half of the practice targets were clear and half were degraded. Subjects were instructed to name each picture as quickly as possible, witnout making errors. The sequence of events within each practice trial was as follows. The first picture appeared on the screen and was removed immediately following the subject's labeling response; 1 sec later, the target picture was exposed and the Klockounter was initiated. The subject's response to the picture stopped the timing cycle and ended the trial. Intertrial intervals were approximately $10 \mathrm{sec}$.

The experimental sequence was initiated immediately following practice. The general procedure and instructions were identical to those used in practice, and no mention was ever made about potential relationships between pictures.

\section{Results}

Mean naming times for target pictures were analyzed by analysis of variance. The factors were relatedness (related vs. unrelated) and stimulus quality (clear vs. degraded). The results were quite clear: Both main effects and the interaction were significant. Naming times for pictures in related pairs $(837 \mathrm{msec})$ were $81 \mathrm{msec}$ faster than those in unrelated pairs $(918 \mathrm{msec})$ $[F(1,39)=42.14, p<.001]$. This finding established the existence of semantic priming effects with pictures. As expected, naming times for degraded targets (973 msec) were $190 \mathrm{msec}$ slower than those for clear targets $(783 \mathrm{msec})[\mathrm{F}(1,39)=159.00, \mathrm{p}<.001]$. Both effects were qualified by their interaction $[F(1,39)=4.25$, $p<.05]$. A comparison of naming times to related vs. unrelated targets separately at each level of stimulus quality yielded significant priming effects at both levels (ps< $<.05$ ). As predicted, the interaction resulted from the relatively larger priming effects for degraded targets $(112 \mathrm{msec})$ than for intact targets $(51 \mathrm{msec})$. Response errors were rare, being less than $2 \%$ for degraded targets and less than $1 \%$ for clear targets.

\section{Experiment 2}

\section{Method}

Subjects. A new group of 20 undergraduates were paid to participate in the experiment.

Materials. The experimental stimuli were 160 common nouns ( 80 primes and 80 targets) typed in lowercase elite type and photographed for slide presentation. The general procedures used to manipulate relatedness and stimulus quality were identical to those used in Experiment 1 except that different camera settings were required (based on pilot work) to produce appropriately degraded word stimuli. All stimuli were photographed at a distance of $24.5 \mathrm{~cm}$, with the camera's focus appropriately set at that distance for clear words and at $30.5 \mathrm{~cm}$ for degraded words.

As in Experiment 1, an incomplete-blocks design was used for assigning stimuli to individual subjects such that every subject saw each target word only once, and, across subjects, each target word appeared equally of ten in all conditions. Since there were 80 different target words in the present experiment, each subject received 20 word pairs in each of the four conditions, for a total of 80 experimental trials. An additional set of 50 unrelated word pairs (half clear and half degraded) was constructed for use on practice trials.

Apparatus and Procedure. The apparatus and procedure were identical to those used in Experiment 1 except that subjects were instructed to read words, rather than to name pictures, as rapidly and accurately as possible.

\section{Results}

An analysis of variance conducted on the mean response times again yielded highly significant effects of both relatedness $[F(1,19)=45.77, p<.001]$ and stimulus quality $[F(1,19)=145.23, p<.001]$, and their interaction $[\mathrm{F}(1,19)=14.25, \mathrm{p}<.005]$. Responses were faster to target words in related pairs $(595 \mathrm{msec})$ than to those in unrelated pairs $(632 \mathrm{msec})$, and response times to degraded targets $(679 \mathrm{msec})$ were slower than those to clear targets $(548 \mathrm{msec})$. As in the previous experiment, a breakdown of the interaction indicated that significant priming effects were obtained with both clear and degraded targets $(p s<.05)$, but 
that the magnitude of the effects differed. The priming effect for clear targets was $19 \mathrm{msec}$; with degraded targets, the effect was $56 \mathrm{msec}$. Errors were again rare: $3.5 \%$ for degraded targets and less than $1 \%$ for clear targets. The direction of this difference suggests that subjects were not trading speed for accuracy, since response times and error rates were positively correlated.

\section{Discussion of Experiments 1 and 2}

The results of Experiment 2 lead to conclusions similar to those reached by Becker and Killion (1977) and Meyer et al. (1975), since semantic relatedness and stimulus quality had significant and interactive effects on the time required for word processing. The present results extend somewhat the generality of previous conclusions about semantic priming, in that subjects need only be instructed to read pairs of actual words for priming effects to occur. Clearly, the occurrence of semantic priming of the automatic type does not depend on the requirement that subjects process nonwords in the priming task.

Similarly, the results of Experiment 1 indicate that simply naming a picture facilitates the naming of a subsequent, related picture, especially if the subsequent picture is visually degraded. Taken together, the results of the first two experiments suggest that semantic priming influences the initial encoding of pictorial and graphemic information in an analogous fashion. (The reader is referred to Seymour, 1976, for a more detailed account of how relatedness and stimulus quality might jointly affect the encoding of pictures, and to Becker and Killion, 1977, for an account of this interaction with words.)

\section{EXPERIMENT 3}

The results of the two previous experiments are qualitatively very similar. In each case, semantic relatedness and stimulus quality affected response times, and they did so interactively, suggesting that encoding processes for picture and word targets are both affected by semantic priming. However, there do appear to be some quantitative differences; picture-picture priming (with clear targets) was $51 \mathrm{msec}$, while word-word priming was only $19 \mathrm{msec}$.

Since different stimuli were used in Experiments 1 and 2, one possible (albeit, rather uninteresting) explanation for the quantitatively different priming effects obtained in the two experiments is simply that the stimulus pairs used in Experiment 1 contained primes and targets that were more strongly related to each other than those used in Experiment 2. A second possibility is that, as a result of being required to process only one type of stimuli, subjects in Experiments 1 and 2 adopted different perceptual strategies for identifying words and pictures that, for some reason, are differ- entially sensitive to the effects of semantic relatedness. We designed the present experiment so as to allow us to rule out these possibilities by requiring each subject to process both pictures and words, and by using the same stimulus items in picture-picture and word-word pairs.

We expected for theoretical reasons, however, that the superiority of picture-picture priming would remain. For example, Rosch (1975) has suggested that pictures may be closer to the central representation of semantic categories than are words. Similarly, Seymour (1976) has argued that information in semantic memory has a strong perceptual component. Paivio (1978) has an even more extreme view, in that he assumes that all semantic information is represented in a nonverbal (imaginal) representational system. Thus, one reasonable explanation for the larger priming effects obtained with picture-picture pairs is that picture targets, relative to word targets, are more compatible with the semantic information activated by a prime, and, consequently, are more sensitive to the effects of semantic priming than are word targets. This view, by itself, would predict that picture targets would be primed more than word targets, regardless of whether the prime is a picture or a word. However, an additional possibility is that the relative closeness of a picture to the central semantic representation of its concept results in pictures' being more effective primes. If this is the case, then the magnitude of the priming effect should vary only as a function of whether the prime is a picture or a word. If both views are correct, then priming in picture-picture pairs should be relatively greater than in word-word pairs, with priming effects for mixed pairs (picture-word and word-picture) intermediate between the two. Inherent in the above predictions is the assumption that priming effects of the automatic type can in fact be obtained with picture-word and word-picture pairs. A demonstration of priming with mixed pairs would provide relatively direct support for the contention that pictures and words access information from a common semantic store.

\section{Method}

Subjects. The subjects were 16 paid undergraduates who did not participate in Experiments 1 and 2.

Materials and Design. Pictorial stimuli were the 32 primes and 32 target pictures used in Experiment 1. The verbal labels for these pictures were typed and photographed as in Experiment 2 for use as word stimuli. All stimuli were clearly visible. An additional set of stimuli was prepared for use on practice trials.

Each subject received 256 trials, with each of the 32 target concepts appearing eight times, once in each of the eight conditions generated by the factorial combination of prime type (word, picture) by target type (word, picture) by relatedness (related, unrelated). Using an incomplete-blocks design, the 256 stimulus pairs were divided into eight blocks of 32 pairs such that (1) each target concept appeared once in each block, and (2) each block contained an equal number of stimulus pairs in each condition. To permit an appropriate analysis of the effects of target repetitions, order of block presentation was 
balanced over subjects so that, across subjects, each stimulus block appeared equally often in each of the eight possible positions (i.e., across subjects, the 256 different stimulus pairs appeared equally often in each block of 32 trials). Each target concept was paired with the same related and unrelated primes throughout the experiment.

The apparatus was identical to that used in the previous experiments.

Procedure. At the beginning of the session, subjects were shown all 164 experimental pictures in a random order and were required to name each. This was done to ensure that the names provided by subjects for pictorial stimuli matched those that would be given for the corresponding word stimuli on experimental trials. Subjects were then given 32 practice trials on the naming task, with all stimulus pairs being of the unrelated type. The practice set included equal numbers of picture-picture, word-word, picture-word, and word-picture pairs. The experimental sequence was initiated immediately following practice, and subjects were given a $10-\mathrm{min}$ rest following the fourth trial block.

\section{Results}

An analysis of variance was conducted on mean response times. The factors were trial blocks (1-4), prime type (picture or word), target type (picture or word), and relatedness (related or unrelated). All factors were within subjects.

The effect of trial blocks was significant $[F(3,45)=$ $12.25, \mathrm{p}<.001]$ and qualified by the Trial Blocks by Target Type interaction $[F(3,45)=6.35, p<.002]$. The relevant data are presented in Table 1 . Tests of simple effects indicated that the influence of trial blocks was significant for both picture targets $[\mathrm{F}(3,45)=8.56$, $p<.001]$ and word targets $[F(3,45)=5.70, p<.003] ;$ however, the effect is somewhat greater for pictures. Further analyses indicated that response times to both pictures and words were significantly slower in Trial Block 1 than in each of the other three blocks (all ps $<.05$ ), which did not differ significantly from each other. These results, then, can best be interpreted as indicating a practice effect that is most evident between the first and second trial blocks. The effect is slightly stronger for pictures, as might be expected based on differences in subjects' preexperimental familiarity with the stimuli; that is, subjects had undoubtedly never seen the exact pictures we used, but had seen the words many times. The most critical point to be made here in regard to trial blocks is that this factor did not interact with relatedness $(F<1.0)$. Subjects saw only unrelated pairs during the practice trials. Therefore, if priming effects obtained with the present procedure are really based on subjects' developing conscious expectations about

Table 1

Mean Response Times (in Milliseconds) for Picture and Word Targets as a Function of Trial Blocks

\begin{tabular}{lcccc} 
& \multicolumn{4}{c}{ Trial Blocks } \\
\cline { 2 - 5 } Target & 1 & 2 & 3 & 4 \\
\hline Picture & 654 & 623 & 629 & 600 \\
Word & 520 & 503 & 503 & 498 \\
\hline
\end{tabular}

the identity of targets, such expectations should emerge and increase across trial blocks (cf. Neely, 1976). This was not the case. In fact, the overall priming effect was $19 \mathrm{msec}$ in Trial Block 1 and $16 \mathrm{msec}$ in Trial Block 4 We thus have some empirical support for the above claim that priming effects in these experiments are of the automatic type.

The analyses also yielded a significant effect of relatedness in the expected direction $[F(1,15)=34.04]$ and an effect of target type $[F(1,15)=340.13]$, with response times to pictures $(626 \mathrm{msec})$ being slower than those to words $(506 \mathrm{msec})$. The main effect of prime type was not significant $(F<1.0)$, but this factor interacted with both relatedness $[F(1,15)=4.55$, $\mathrm{p}<.05]$ and target type $[\mathrm{F}(1,15)=9.33, \mathrm{p}<.01]$. The interaction of relatedness and target type was also significant $[F(1,15)=6.72, p<.02]$. All of these effects are best viewed in the context of the significant three-factor interaction of Relatedness by Prime Type by Target Type $[F(1,15)=7.71, p<.02]$. The relevant data are presented in Table 2.

Subsequent breakdowns of this interaction indicated that for picture targets, the type of prime significantly influenced the magnitude of the priming effect $[F(1,15)=7.12, p<.02]$. Priming effects were $31 \mathrm{msec}$ with picture primes and $13 \mathrm{msec}$ with word primes. However, the 13-msec effect obtained with word primes was still statistically significantly $[F(1,15)=36.07$, $\mathrm{p}<.001]$. For word targets, significant priming effects were again obtained with both word and picture primes $[F(1,15)=29.43, p<.001]$, but the magnitude of the effect did not differ as a function of prime type $(\mathrm{F}<1.0)$. These effects, although significant, were rather small: $8 \mathrm{msec}$ with picture primes and $10 \mathrm{msec}$ with word primes.

\section{Discussion}

The finding that significant priming effects were obtained with both picture-word and word-picture pairs is consistent with the view that pictures and words make contact with a common semantic system. The general pattern of results across mixed and unmixed pairs, however, is not consistent with our initial predictions. Priming effects for picture-picture pairs were indeed larger than those for word-word pairs, but priming on mixed pairs was no greater than that on word-word pairs. If pictures are generally more effective primes than words, and/or picture targets receive more priming in general than do words, then priming effects on one or both of the mixed pairs should have been greater than that on word-word pairs. The data appear to necessitate some additional assumptions about the mechanisms that underlie picture-picture priming effects.

A model that addresses picture processing in some detail, and that therefore provides a framework for conceptualizing the present results, has been proposed by Seymour $(1973,1976)$. The model is an extension 
Table 2

Mean Response Times (in Milliseconds) for Related and Unrelated Picture and Word Targets as a Function of Prime Type

\begin{tabular}{ccccccrc}
\hline & \multicolumn{4}{c}{ Target Type } \\
\cline { 2 - 7 } & \multicolumn{4}{c}{ Picture } & \multicolumn{3}{c}{ Word } \\
\cline { 2 - 7 } Prime & Related & Unrelated & Priming Effect & Related & Unrelated & Priming Effect \\
\hline Picture & 607 & 638 & 31 & 506 & 514 & 8 \\
Word & 624 & 637 & 13 & 497 & 507 & 10 \\
\hline
\end{tabular}

of Morton's (1969) logogen model, with an elaboration of the encoding and recoding processes that act on both pictures and words. Since a full description of this model is beyond the scope of this paper, we will restrict our discussion only to those aspects most critical for conceptualizing the differential priming effects obtained for pictures and words.

Seymour $(1973,1976)$ postulates an interface structure for picture processing, the iconogen system, which is analogous to Morton's (1969) logogen system for words. Logogens and iconogens are pattern recognizers that are boosted to threshold value when their defining features are present in the graphemic and pictorial codes for incoming word and picture stimuli, respectively. According to the model, there is a single semantic system that connects in a feedback loop with both the iconogen and logogen systems.

Under the present task conditions, we assume that subjects must eventually arrive at a phonemic code for both pictures and words in order to produce a verbal output. To arrive at a phonemic code for words, the model posits a graphemic encoding process followed directly by a graphemic-phonemic conversion process mediated by the logogen system. For pictures there is a pictorial encoding process, a pictorial-semantic conversion process mediated by the iconogen system, and, finally, a semantic-phonemic conversion process mediated by the logogen system. It can be noted at this point that the longer overall response times for picture naming relative to word naming obtained across the first two experiments, and within the third, would be expected if an additional recoding step, as posited by this model, is required for picture naming (see also Dhawan \& Pellegrino, 1977; Nelson, Reed, \& McEvoy, 1977). As for the role of semantic priming in picture and word processing, priming is assumed to result from a lowering of the "evidence requirements" for logogens and iconogens of word targets and picture targets, respectively, following the processing of a semantically related prime. The lowered evidence requirements for related targets is assumed by the model to facilitate early encoding, which is consistent with the interactions between stimulus quality and semantic relatedness obtained in the first two studies. "Early encoding" refers more specifically to the graphemicphonemic conversion for words and the pictorialsemantic conversion for pictures. (It should be noted that the model also makes provision for an additional locus of priming effects for pictures only, the semanticphonemic conversion stage. This assumption is neither necessary nor sufficient for explaining the present data, and we know of no other data that specifically necessitate the assumption.)

Turning now to the pattern of priming effects obtained in this experiment, for pictures in related pairs there is assumed to be an additional relationship between primes and targets (not present for word-word pairs) that can further lower the evidence requirement for the iconogens of categorically related targets. This relationship is among the visual features common to pictorial representations of objects that belong to the same semantic category (Rosch, Mervis, Gray, Johnson, \& Boyes-Braem, 1976). Since iconogens sample visual features, and pictures of items (particularly highly typical ones) in the same semantic category share at least some visual features in common, the iconogen for a target picture in a related pair should accrue some evidence during the initial encoding of the pictorial prime. This is, of course, not the case for words, since graphemic representations of items from the same semantic category do not share visual features in any systematic way. Thus, while priming with both picture and word pairs is assumed to result from input from the semantic system to the iconogen and logogen systems, respectively, for related picture-picture pairs, an additional lowering of evidence requirements in the iconogens may occur that results exclusively from "visual priming." While this visual priming interpretation was not directly tested in these experiments, it can account for the finding that priming effects were greater for picture-picture pairs than for all of the other three types of pairs, which did not differ from each other; visual priming should only occur when both the prime and target are pictures.

In conclusion, the present results clearly demonstrate that semantic priming can facilitate the identification of both pictures and words. The data further indicate that the encoding of both types of stimuli is affected in an analogous interactive manner by stimulus quality and semantic relatedness, and that both picture and word priming are mediated by the same semantic system. However, when picture targets are preceded by categorically related picture primes, there is an additional boost in the priming effect that is attenuated when 
either the prime or the target (or both) is presented graphemically. This suggests the possibility that with related picture-picture pairs, subjects can make use of the overlap in visual features between primes and targets that results from the general commonalities in appearance among highly typical members of the same semantic category.

\section{REFERENCES}

Anderson, J. R. Arguments concerning representations for mental imagery. Psychological Review, 1978, 85, 249-277.

BeCKer, C. A., \& KiLlion, T. H. Interaction of visual and cognitive effects in word recognition. Journal of Experimental Psychology: Human Perception and Performance, 1977, 3, 389-401.

Collins, A. M., \& Loftus, E. F. A spreading-activation theory of semantic processing. Psychological Review, 1975, 82, 407-428.

Dhawan, M., \& Pellegrino, J. W. Acoustic and semantic interference effects in words and pictures. Memory \& Cognition, 1977, 5, 340-346.

Fischle R, I. Associative facilitation without expectancy in a lexical decision task. Journal of Experimental Psychology: Human Perception and Performance, 1977, 3, 18-26.

HAGEN, M. A. An outline of an investigation into the special character of pictures. In H. L. Pick \& E. Saltzman (Eds.), Modes of perceiving and processing information. Hillsdale, N.J: Erlbaum, 1978.

Holland, J. D. Features and semantic memory: Set-theoretic or network model? Psychological Review, 1975, 82, 154-155.

Meyer, D. E., Schvaneveldt, R. W., \& Ruddy, M. G. Loci of contextual effects on visual word-recognition. In P. M. A. Rabbitt \& S. Dornic (Eds.), Attention and performance $V$. New York: Academic Press, 1975.

Morton, J. Interaction of information in word recognition. Psychological Review, 1969, 76, 165-178.

NeELY, J. H. Semantic priming and retrieval from lexical memory: Evidence for facilitatory and inhibitory processes. Memory \& Cognition, 1976, 4, 648-654.

NeELy, J. H. Semantic priming and retrieval from lexical memory: Roles of inhibitionless spreading activation and limited-capacity attention. Journal of Experimental Psychology: General, 1977, 106, 226-254.

Nelson, D., Reed, V., \& McEvoy, C. Learning to order pictures and words: A model of sensory and semantic encoding. Journal of Experimental Psychology: Human Learning and Memory, 1977, 3, 485-497.

Paivio, A. A dual coding approach to perception and cognition. In H. L. Pick \& Saltzman (Eds.), Modes of perceiving and processing information. Hillsdale, N.J: Erlbaum, 1978.

Posner, M. I., \& Snyder, C. R. R. Attention and cognitive control. In R. L. Solso (Ed.), Information processing and cognition: The Loyola symposium. Hillsdale, N.J: Erlbaum, 1975.

Rosch, E. Cognitive representations of semantic categories. Journal of Experimental Psychology: General, 1975, 104, 192-233.

Rosch, E., Mervis, C. B., Gray, W. D., Johnson, D. M., \& Boyes-Braem, P. Basic objects in natural categories. Cognitive Psychology, 1976, 8, 382-439.

Sanford, A. J., Garrod, S., \& Boyle, J. M. An independence of mechanism in the origins of reading and classification-related semantic distance effects. Memory \& Cognition, 1977, 5, 214-220.

Seymour, P. H. K. A model for reading, naming, and comparison. British Journal of Psychology, 1973, 64, 35-49.

Seymour, P. H. K. Contemporary models of the cognitive processes: 11. Retrieval and comparison operations in permanent memory. In V. Hamilton \& M. D. Vernon (Eds.), The development of cognitive processes. New York: Academic Press, 1976.

Shulman, H. G., \& Davison, T. C. B. Control properties of semantic coding in a lexical decision task. Journal of Verbal Learning and Verbal Behavior, 1977, 16, 91-98.

(Received for publication August 10, 1978; revision accepted May 16, 1979.) 